\title{
Influences of nutrition information on fast food consumption among undergraduates
}

\author{
*Vijayakumaran, R.K. and Nur Amalina, S. \\ Nutrition and Dietetics Department, School of Health Sciences, Health Campus. Universiti Sains Malaysia, \\ 16150 Kubang Kerian, Kelantan, Malaysia
}

\begin{abstract}
Article history:
Received in revised form: 19

December 2017

Available Online: 24

December 2017

Keywords:

Fast food,

Nutrition information,

Consumption,

Nutrition intake,

University student
\end{abstract}

Received: 30 November 2017

Accepted: 21 December 2017

\section{DOI:}

https://doi.org/10.26656/fr.2017.2(3).288

\begin{abstract}
This study was carried out to determine the influences of providing nutrition information on fast food restaurant menus, especially among Malaysian undergraduates, who often eat outside the campus during the semester. A validated questionnaire, adapted from previous studies was used to determine the general perception of nutrition information and nutrient intake when eating at fast food restaurants. A total of 185 undergraduates from three different schools participated - medical sciences $(n=54,29.2 \%)$, dentistry, $(n=54,29.2 \%)$, health sciences $(n=77,41.6 \%)$ in a university. In general, the majority of the undergraduates ate fast food at least once a week $(n=105,56.8 \%)$ and most of them preferred to eat outside on weekends $(\mathrm{n}=156,84.3 \%)$. Majority perceived that it was important to provide nutrition information at fast food restaurant $(n=183,98.9 \%)$. The mean for calorie, fat and sodium composition of their food choices were significantly different between before and after providing nutrition information of food items that they intended to purchase $(p<0.001)$. Student's intention to purchase definitely differed when they were well informed about the nutrition value of food.
\end{abstract}

\section{Introduction}

Lifestyle changes have taken place in many countries worldwide over the last few decades have an impact on food consumption patterns. One of the most prominent trends is the increase in outside food consumption (Jaworowska et al., 2013). In many countries, restaurants especially fast food outlets have been criticized by nutritionists, health crusaders and the media over its offering of high-fat foods (Totten et al., 2009), and its impact on obesity. Malaysia is known as Asia's fattest country (McPherson, 2014), with the latest statistics indicating that overweight and the obese make up nearly half its 30 million population (National Health and Morbidity Survey, 2015). Currently, the prevalence of obesity in Malaysia is higher than the world's prevalence's rate of $13.0 \%$ in 2014 (World Health Organisation, 2016). As the number of people with obesity increases, the alarming trend does not only require immediate revision of public health policies, but also supportive environment for Malaysians to work towards practicing healthier lifestyle (National Health and Morbidity Survey, 2015).

Mandatory nutrition labelling was enforced in Malaysia in 2003 (Ministry of Health, 2010), and fast food outlets have been providing nutritional information of food items to their customer since then. The decision to provide nutritional information is welcomed by many, as studies have reported that providing nutrition information at a point of purchase in food establishment had encouraged healthier choices among consumer (Coulson, 2000; Nayga, 2000; Lin et al., 2003; Bassett et al., 2008). However, a significant concern on the use of nutrition information is that it may not be persuasive enough to encourage healthy eating habits (Guthrie et al., 1999; Elbel et al., 2011). This is because not many use the nutrition information in deciding what to purchase (Roberto et al., 2009), mainly due to the fact that the nutritional information is somewhat hidden or not provided at the point of purchase (Poulain et al., 2014).

Increased consumption of fast food was also associated faster pace of life in big cities, leading people to find quicker meal solution during shortened lunch hours (Hanson, 2002), which fits well with university or college student's lifestyle. University or college students, in particular, tend to have a high frequency of eating out and were likely to choose fast food when they eat out (Bipasha and Goon, 2014). Studies have indicated that university students tend to eat fast food at least once weekly (Driskell et al., 2006), making fast food restaurants their favorite eating place. Eating fast food 
frequently is often related to high consumption of fatty fast food and sugary soft drinks (Bipasha and Goon, 2014). Their diet tends to be also lower in fibre, calcium, fruits, and vegetables (Venderlee and Hammond, 2014).

Knowing that obesity is on the rise among adults (National Health and Morbidity Survey, 2015), this study was initiated because there is limited information on whether university students (young adults) in Malaysia use nutrition information whenever they eat out, especially at fast food outlets. It is even more important to conduct this study because eating out has become a part of university student's busy lifestyle. As such, this study was conducted to determine the influences of nutritional information of fast food restaurant menu on consumption among undergraduates of Universiti Sains Malaysia, Health Campus, Malaysia.

\section{Materials and methods}

\subsection{Sampling method}

This research assessed university student's perception on nutrition information, influences of providing nutrition information on their food choices and compared the types of food and its nutrient content of food fast which they intend to purchase with or without provision of nutrition information. This study was conducted among undergraduates of Universiti Sains Malaysia at Health campus, as there are a number of fast food restaurants within $3 \mathrm{~km}$ radius of the university, making these fast food outlets a favorite among them. The selection criteria include undergraduates from the school of dentistry, medical sciences and health sciences, aged 19-30 years old (young adults), must consume fast food, live on campus, does not have any dietary restrictions and willing to participate voluntarily. The campus's undergraduate population was used to calculate the sample size with the 'Raosoft' sample size calculator (www.raosoft.com/samplesize), which indicated a total of 142 participants should be included. However, a total of 220 questionnaires were distributed and 35 participants were considered dropouts due to incomplete questionnaires, making the final total as 185 participants.

\subsection{Data collection}

Data collection was carried out for approximately 2 months, after obtaining ethical approval from the Universiti Sains Malaysia Research Ethics Committee (Human Studies), during teaching and learning weeks. A self-administered questionnaire was distributed to participants at all the residential colleges on campus. The potential participants were briefed on the purpose of the study, the study procedures and informed consent form were given. Once they consented to participate, they were asked to fill in questionnaires.

The questionnaire was adapted from previous studies (Martinez et al., 2012; Din et al., 2017) because the content had to be relevant to the particular group (university students) and the type of food on the menu was accessible to the participants. The questionnaire focused on the general perception of nutrition information, use of nutrition information, nutrient composition of food selected with and without nutrition information on the menu. The questionnaire was prepared in English and Malay (back translation was used) to allow participants to answer in their preferred language.

Part A in the questionnaire included participant's socio-demographic factors (eg. age, gender, programme, food consumption and purchasing information), as these factors were often associated with usage of nutrition information (Cranage et al., 2004; Martinez et al., 2012; Watson and Anstrom, 2013). In part B, participants were provided pictures of fast food menus items without the nutrition information. They were requested to select menu items from the list provided, similar to which they would order from a fast food restaurant for a typical meal, including a main dish, a side order, and a drink.

Part $\mathrm{C}$ included 18 questions on general perception and use of nutrition information, such as 'Providing nutrition information in fast food restaurant is important for me' and 'Nutrition information affects the food choices that I make when eating at fast food outlets? The part $\mathrm{C}$ questions were asked before proceeding with Part D (which contains same pictures as part B, but with nutritional information) to access their perception before they looked at the nutritional information. Part $\mathrm{C}$ was measured on a 5-point Likert scale (1- strongly disagree, 5 -strongly agree). Mean score of higher than 3 indicated that they perceived nutrition information as important, whereas a mean score of below 3 indicated that they did not perceive nutrition information as important. The questions were adapted from questions used in previous studies by Din et al. (2017) and Martinez et al. (2012).

In part $\mathrm{D}$, participants were provided with the same pictures as part $\mathrm{B}$, but with the nutrition information on macronutrients- energy (kcal), carbohydrate (grams), protein (grams), fat (grams) and salt (grams). These nutrients are mandatory in the food labelling, and often used by college or university students when selecting foods (Chu et al., 2009). The nutrition information of each food item was obtained from few fast food restaurants in Malaysia and on from their website. The list of the menu item in a fast food outlet was used to examine the influence of labelling - adapted from survey 
questionnaire on the effects of calorie information on fast food menu by Watson and Anstrom (2013). Both part B and D was adapted from Watson and Anstrom (2013). Part B (without the nutritional information) was provided before proceeding with part $\mathrm{D}$ (with nutritional information) with a short gap (while they answer part C) to examine the influence of nutrition information in selecting food from the same menu, but with or without nutritional information.

\subsection{Data analysis}

Data were statistically analyzed using the IBM Statistical Package for Social Sciences (SPSS) version 22. Demographic data were analyzed using the descriptive statistics, participant's general perception was determined by calculating the mean score of all statements provided in the questionnaire. Mean for each aspect of nutrient intake were analyzed and tabulated. Paired T-test was then performed to find out the mean differences of overall nutrient composition for each component comprised of total calorie, total fat and total sodium between menu without nutrition information (part B) and a menu with nutrition information (part D) was provided.

\section{Results}

\subsection{General}

The mean age of participants in this study was approximately 22 years old. In terms of gender, there were more female participants compared to males, 109 (58.9\%) out of 185 participants. In terms of ethnicity, majority of the participants were Malays $77.3 \%(n=143)$ followed by Chinese $13.0 \%(\mathrm{n}=24)$, Indians $5.4 \%(\mathrm{n}=10)$ and of Other ethnicities $4.3 \%(n=8)$. Slightly higher number of participants were from the School of Health Science $41.6 \%(\mathrm{n}=77)$ in comparison to participants from School of Medical Sciences 29.2\% $(n=54)$ and School of Dentistry $29.2 \% \quad(n=54)$. In terms of consumption, the majority of the participants preferred to eat outside the campus during the weekend $(84.3 \%$, $\mathrm{n}=156$ ) compared to weekdays. Fast food outlets were the second favorite place $(18.5 \%, \mathrm{n}=38)$ to consume after hawker stalls $(55.6 \%, \mathrm{n}=114)$, food courts $(16.6 \%, \mathrm{n}=34)$ and full-service restaurants $(9.3 \%, \mathrm{n}=19)$ when they purchased food outside the campus. Majority reported that they consumed fast food at least once a week $(56.8 \%, \mathrm{n}=105)$, followed by not at all in a week $(29.2 \%$, $\mathrm{n}=54)$, twice a week $(2.7 \%, \mathrm{n}=5)$. They usually purchase fast food by going to the outlets $(93 \%, n=173)$, by telephoning the delivery service $(5.9 \%, \mathrm{n}=11)$ and online purchase $(0.5 \%, \mathrm{n}=1)$.

\subsection{Perception of nutrition information}

Overall, they were asked to what extend nutritional information has an impact on their food selection. Their answers indicated that nutritional information only 'sometimes' affect their food selection $(72.3 \%, \mathrm{n}=134)$, followed by 'never' $(13.5 \%, \mathrm{n}=25)$ and 'always' $(14.1 \%$, $\mathrm{n}=26$ ) when they selected food. Besides, participants 'strongly agreed' that providing nutrition information at fast food restaurants was important to them, as it helped them to understand about food choices and it promoted healthy eating (shown in Table 1).

Table 1. Perception on the importance of providing nutrition information

\begin{tabular}{|c|c|c|c|}
\hline Item & $\mathrm{N}$ & *Mean & Interpretation \\
\hline $\begin{array}{l}\text { Important for me and } \\
\text { other people }\end{array}$ & 185 & 4.11 & Strongly agree \\
\hline $\begin{array}{l}\text { Helps understand better } \\
\text { about food choices }\end{array}$ & 185 & 4.23 & Strongly agree \\
\hline $\begin{array}{l}\text { Good effort to promote } \\
\text { healthy eating }\end{array}$ & 185 & 4.35 & Strongly agree \\
\hline \multicolumn{4}{|c|}{$\begin{array}{l}\text { * Mean score }>3.00 \text { indicates agree and }<3.00 \text { indicates disagre } \\
\text { * Mean was calculated based on rating points participants an- } \\
\text { swered on Likert scale: } \\
1=\text { Strongly disagree, } 2=\text { Disagree, } 3=\text { Neither, } 4=\text { Agree, } 5= \\
\text { Strongly agree }\end{array}$} \\
\hline
\end{tabular}

\subsection{Usage of nutrition information}

Majority of the participants, $54.1 \%(n=100)$ did not use the nutrition information provided at the fast food restaurant because they were unaware, followed by $38.4 \%(n=71)$ who claimed that they only noticed the nutrition information and ignored it. However, few of them $7.6 \%(n=14)$ used the nutrition information as a guideline to purchase their meals.

\subsection{Nutrient composition of food selected}

For menu without nutrition information, the mean for total kcal was $1187.34 \mathrm{kcal}$, the mean for total fat was $52.36 \mathrm{~g}$, while the mean for total sodium was $7.29 \mathrm{~g}$. As for the menu with nutrition information, the mean total kcal was $815.78 \mathrm{kcal}$, the mean total fat was 35.99 $\mathrm{g}$, while the mean total sodium was $5.88 \mathrm{~g}$. This indicated that the mean for nutrients - calorie, fat and sodium of food selected on the menu without nutrition information was higher than the nutrient intake of food selected with nutrition information. A paired $t$-test showed that the mean differences between nutrient intake (calorie, fat, and sodium) of food selected on the menu without and with nutrition information was statistically significant at $p<0.001$. Results are presented in Table 2. 
Table 2. Comparison of overall nutrient composition food selected with and without nutrition information

\begin{tabular}{cccccc}
\hline Variable & $\begin{array}{c}\text { Without NI* } \\
\text { Mean (SD) }\end{array}$ & $\begin{array}{c}\text { With NI** } \\
\text { Mean (SD) }\end{array}$ & Mean of difference $(95 \% \mathrm{CI})$ & $\begin{array}{c}t \text {-test } \\
(\mathrm{df})\end{array}$ & $p$ value*** \\
\hline Total kcal & $1187.34(597.23)$ & $815.78(582.46)$ & $371.56(294.46,448.40)$ & $9.539(184)$ & $<0.001$ \\
Total fat & $52.36(28.59)$ & $35.98(26.87)$ & $16.38(12.46,20.29)$ & $8.250(184)$ & $<0.001$ \\
Total sodium & $7.29(5.62)$ & $5.88(5.21)$ & $1.41(0.69,2.14)$ & $3.831(184)$ & $<0.001$ \\
\hline
\end{tabular}

* With NI = Mean with Nutritional Information

** Without NI $=$ Mean without Nutritional Information

$* * * \mathrm{p}$ value $=$ paired $\mathrm{t}$-test

\section{Discussion}

In terms of general consumption, findings of this study were similar to other studies, which indicated that majority of students tend to eat out at least once a week and usually during weekends (Gan et al., 2011). Hawker stalls or street stalls were their main choice to eat, which could be influenced by the availability of food from night market on Fridays - walking distance from the residential colleges. However, another study among the students indicated that they ate at hawker stalls on a daily basis (Gan et al., 2011).

Interestingly, this was followed by fast food restaurant mainly because of many fast food restaurants such as Kentucky Fried Chicken and Pizza Hut are available nearby the campus, which is also a walking distance from the residential colleges. Majority of the participants consumed fast food at least once in a week, which was similar to the study reported by Gan et al. (2011), whereby the majority of the students ate out at fast food restaurant one to three times a month followed by once a week. They choose to purchase fast food directly at the fast food outlets, as many fast food restaurants are nearby to the campus within a walking distance, similar to a study reported by Farzana et al. (2011).

Majority of the participants perceived that it was important to provide nutrition information and a good effort in promoting healthy eating, which was also highlighted by Harnack et al. (2008) and Smith et al. (2000). The students shared the same perception with another group of people like working adults and when purchasing daily groceries (Smith et al., 2000; Harnack et al., 2008). Since these students were studying in the area of medical and health sciences, it was expected that they may tend to perceive the importance of providing nutrition information as crucial. This is because knowledge is strongly connected with choosing a particular food (Drichoutis, 2005; Drichoutis et al., 2006; Krukowski et al., 2006).

Previous findings indicated that when nutrition information was available at the point of sale, some proportion of consumers used them (Wethington et al., 2013). Studies also found that people who were highly motivated to use nutrition information would often attempt to balance their consumption during eating occasions (Howlett et al., 2009). Perhaps, if the nutrition information was attractively presented at a point of purchase, it may have increased the chances to use the nutrition information. Majority of the participants did not use the nutritional information provided, as they were unaware of the nutrition information. In the agreement, studies have indicated that consumers may not be aware of the position of nutrition information at fast food restaurants or it is not visible to them (Wootan et al., 2006; Azlina et al., 2011). Besides, Krieger et al. (2013) suggested that some who noticed the nutrition information may not use it, due to lack of awareness, lack of interest or limited understanding.

Calorie composition of food selected significantly differed between without and with the nutrition information, which was consistent with previous findings (Chu et al., 2009; Roberto et al., 2010; Dumanovsky et al., 2011). This is because consumers tend to underestimate caloric content of higher caloric items. Therefore, nutrition information has a greater impact on selecting the food (Bates et al., 2009). Besides, nutrition information is seen as a valuable resource for those who rely on food from outside and would like to make healthier choices (Dumanovsky et al., 2011). Frequent exposure to the nutrition information provided at restaurant setting may affect and attract consumers, especially university students when they eat out.

\section{Conclusion}

In summary, a total of 185 undergraduates from three different schools participated in this study. They consumed fast food at least once a week $(n=105,56.8 \%)$ and most of them preferred to eat outside during weekends ( $\mathrm{n}=156,84.3 \%)$. Majority perceived that it was important to provide nutrition information at fast food restaurant $(\mathrm{n}=183,98.9 \%)$. The most important finding was the mean for calorie, fat and sodium composition of their food choices, which was 
significantly different between before and after providing nutrition information of food items that they intended to purchase $(\mathrm{p}<0.001)$.

The finding of this study revealed that young adults in Malaysian university, especially with the Medical and Health sciences background positively perceived the importance of having nutrition information at a restaurant setting particularly at fast food restaurants as an effort to promote a healthy eating. However, most of them were unaware of the nutrition information provided at the fast food outlet. Student's lifestyle, the conveniences and the availability of food may have prompted them to eat at fast food outlets, especially when the campus is nearby to various fast food restaurants. The findings on the intention to purchase with and without nutrition information were indeed crucial. Their intention to purchase food with higher calories, fat and sodium changed when nutritional information was provided.

Student's intention to purchase definitely differed when they were well informed on the nutrition value of the food. Therefore, improvement in terms of the effective ways of providing the nutrition information is necessary at fast food outlets. Nutrition information should not only be placed at the point of purchase. Besides, awareness programs among the students are needed to enhance their awareness of nutrition information. Future study should take into account of their actual food purchasing and eating habits to understand their eating behavior better, more food items should be included and the relationship between health consequences (such as obesity) and the use of nutrition information should be focused.

\section{Acknowledgement}

The researcher would like to thank the schools which granted the permission to carry out the research and all the participants who took part.

\section{References}

Azlina, S., Kamaruzaman, J., Zetty Madina, M.Z., Mushaireen, M., Khazainah, K., Norzaidah, N. and Hamid, M. (2011). Customer's Perception Towards McDonald's Icon-Based Nutritional Labels. World Applied Sciences Journal, 12, 01-07.

Bassett, M.T., Dumanovsky, T., Huang, C., Silver, L.D., Young, C., Nonas, C. and Frieden, T.R. (2008). Purchasing behavior and calorie information at fastfood chains in New York City, 2007. American Journal of Public Health, 98(8), 1457-1459. https:// doi.org/10.2105/AJPH.2008.135020
Bipasha, M.S. and Goon, S. (2014). Fast food preferences and food habits among students of private universities in Bangladesh. South East Asia Journal of Public Health, 3(1), 61-64. https:// doi.org/10.3329/seajph.v3i1.17713

Chu, Y.H., Frongillo, E.A., Jones, S.J. and Kaye, G.L. (2009). Improving patrons' meal selections through the use of point-of-selection nutrition labels. American Journal of Public Health, 99(11), 20012005. https://doi.org/10.2105/AJPH.2008.153205

Cranage, D.A., Conklin, M.T. and Lambert, C.U. (2004). Effect of Nutrition Information in Perceptions of Food Quality, Consumption Behavior and Purchase Intentions. Journal of Foodservice Business Research, 7(1), 43-61. https://doi.org/10.1300/ J369v07n01_04

Coulson, N.S. (2000). An application of the stages of change model to consumer use of food labels. British Food Journal, 102(9), 661-668. https:// doi.org/10.1108/00070700010362031

Din, N., Zahari, M.S.M. and Shariff, S.M. (2017). Nutritional labelling in Malaysian full service restaurant menu. Journal of ASIAN Behavioural Studies, 2(2), 47-55. https://doi.org/10.21834/ jabs.v2i2.178

Drichoutis, A.C. (2005). Nutrition knowledge and consumer use of nutritional food labels. European Review of Agriculture Economics, 32(1), 93-118. https://doi.org/10.1093/erae/jbi003

Drichoutis, A.C., Lazaridis, P. and Nayga Jr, R.M. (2006). Consumers' use of nutritional labels: a review of research studies and issues. Academy of Marketing Science Review, 2006(1), 1-22.

Driskell, J.A., Meckna, B.R. and Scales, N.E. (2006). Differences exist in the eating habits of university men and women at fast-food restaurants. Nutrition Research, 26(10), 524-530. https://doi.org/10.1016/ j.nutres.2006.09.003

Dumanovsky, T., Huang, C.Y., Nonas, C.A., Matte, T.D., Bassett, M.T. and Silver, L.D. (2011). Changes in energy content of lunchtime purchases from fast food restaurants after introduction of calorie labelling: cross sectional customer surveys. British Medical Journal, 343, 4464. https://doi.org/10.1136/ bmj.d4464

Elbel, B., Gyamfi, J. and Kersh, R. (2011). Child and adolescent fast-food choice and the influence of calorie labeling: a natural experiment. International Journal of Obesity (Lond), 35(4), 493-500. https:// doi.org/10.1038/ijo.2011.4

Farzana, Q.H., Rozhan Abu, D. and Sabarudin, Z. (2011). Consumers' preference and consumption 
towards fast food: Evidences from Malaysia. Business Management Quarterly Review, 2(1), 1426.

Gan, W.Y., Mohd, N., Zalilah, M. and Hazizi, A. (2011). Differences in eating behaviours, dietary intake and body weight status between male and female Malaysian university students. Malaysian Journal of Nutrition, 17(2), 213-228.

Guthrie, J.F., Derby, B.M. and Levy, A.S. (1999). What people know and do not know about nutrition. In America's eating habits: Changes and consequences, p. 243-290. New York, NY: The U.S. Department of Agriculture's (USDA) Economic Research Service.

Hanson, R. (2002). Turkey HRI food service sector report 2002. USA: USDA Foreign Agricultural Service Gain Report TU2012.

Harnack, L.J., French, S.A., Oakes, J.M., Story, M.T., Jeffery, R.W. and Rydell, S.A. (2008). Effects of calorie labeling and value size pricing on fast food meal choices: results from an experimentaltrial. International Journal of Behavioral Nutrition and Physical Activity, 5(1), 63. https:// doi.org/10.1186/1479-5868-5-6

Howlett, E.A., Burton, S., Bates, K. and Huggins, K. (2009). Coming to a Restaurant Near You? Potential Consumer Responses to Nutrition Information Disclosure on Menus. Journal of Consumer Research, 36(3), 494-503. https:// doi.org/10.1086/598799

Jaworowska, A., Blackham, T., Davies, I.G. and Stevenson, L. (2013). Nutritional challenges and health implications of takeaway and fast food. Nutrition Review, 71(5), 310-318. https:// doi.org/10.1111/nure.12031

Krieger, J.W., Chan, N.L., Saelens, B.E., Ta, M.L., Solet, D. and Fleming, D.W. (2013). Menu labeling regulations and calories purchased at chain restaurants. American Journal of Preventive Medicine, 44(6), 595-604. https://doi.org/10.1016/ j.amepre.2013.01.031

Krukowski, R.A., Harvey-Berino, J., Kolodinsky, J., Narsana, R.T. and Desisto, T.P. (2006). Consumers may not use or understand calorie labeling in restaurants. Journal of American Dietetic Assocation, 106(6), 917-920. https://doi.org/10.1016/ j.jada.2006.03.005

Martinez, O.D., Roberto, C.A., Kim, J.H., Schwartz, M.B. and Brownell, K.D. (2012). A Survey of undergraduate student perceptions and use of nutrition information labels in a university dining hall. Health Education Journal, 72(3), 319-325. https://doi.org/10.1177/0017896912443120
McPherson, K. (2014). Reducing the global prevalence of overweight and obesity. The Lancet, 384, 728730. https://doi.org/10.1016/S0140-6736(14)60767-4

Ministry of Health (2010). Gude to Nutrition Labellig and Claims. Retrieved from: http://fsq.moh.gov.my/ v5/ms/guide-to-nutrition-labelling-and-claims-2010$2 /$.

Nayga, R.M.Jr. (2000). Nutrition knowledge, gender, and food label use. The Journal of Consumer Affairs, 341, 97-112. https://doi.org/10.1111/j.17456606.2000.tb00086.x

Poulain, J.-P., Tibère, L., Laporte, C. and Mognard, E. (2014). Malaysian Food Barometer. Malaysia: Taylor's Press

Roberto, C.A., Agnew, H. and Brownell, K.D. (2009). An observational study of consumers' accessing of nutrition information in chain restaurants. American Journal of Public Health, 99(5), 820-821. https:// doi.org/10.2105/AJPH.2008.136457

Roberto, C.A., Larsen, P.D., Agnew, H., Baik, J. and Brownell, K.D. (2010). Evaluating the impact of menu labeling on food choices and intake. American Journal of Public Health, 100(2), 312-318. https:// doi.org/10.2105/AJPH.2009.160226

Smith, S.C., Taylor, J.G. and Stephen, A.M. (2000). Use of food labels and beliefs about diet-disease relationships among university students. Public Health Nutrition, 3(2), 175-182. https:// doi.org/10.1017/S1368980000000203

Totten, J.W., McKay, S. and Konell, S. (2009). Another look at consumers' ratings of quick-service restaurant meals. Journal of Foodservice Business Research, 12(4), 292-316. https:// doi.org/10.1080/15378020903344240

Watson, K. and Anstrom, C. (2013). To What Extent Does Posted Nutrition Information in Fast Food Restaurants Influence Consumer Food Choices? Journal of the Academy of Nutrition and Dietetics, 9 (113), 83. https://doi.org/10.1016/j.jand.2013.06.290

Wethington, H., Maynard, L.M. and Blanck, H.M. (2013). Use of calorie information at fast food and chain restaurants among US youth aged 9-18 years, 2010. Journal of Public Health (Oxford), 35(3), 354360. https://doi.org/10.1093/pubmed/fdt049

World Health Organisation (WHO) (2016). Obesity and Overweight Fact Sheet. Retrieved on December 2016 from: http://www.who.int/mediacentre/ factsheets/fs311/en/.

Wootan, M.G., Osborn, M. and Malloy, C.J. (2006). Availability of point-of-purchase nutrition information at a fast-food restaurant. Preventive Medicine, 43(6), 458-459. https://doi.org/10.1016/ j.ypmed.2006.07.008 